\title{
Kinetics and Mechanistic Study of Permanganate Oxidation of Fluorenone Hydrazone in Alkaline Medium
}

\author{
Ahmed Fawzy, ${ }^{1,2}$ Saleh A. Ahmed,, ${ }^{1,2}$ Ismail I. Althagafi, \\ Moataz H. Morad, ${ }^{1}$ and Khalid S. Khairou ${ }^{1}$ \\ ${ }^{1}$ Chemistry Department, Faculty of Applied Science, Umm Al-Qura University, Makkah 21955, Saudi Arabia \\ ${ }^{2}$ Chemistry Department, Faculty of Science, Assiut University, Assiut 71516, Egypt \\ Correspondence should be addressed to Ahmed Fawzy; afsaad13@yahoo.com and Saleh A. Ahmed; saleh_63@hotmail.com
}

Received 27 April 2016; Revised 9 June 2016; Accepted 19 June 2016

Academic Editor: Claudio Fontanesi

Copyright (C) 2016 Ahmed Fawzy et al. This is an open access article distributed under the Creative Commons Attribution License, which permits unrestricted use, distribution, and reproduction in any medium, provided the original work is properly cited.

\begin{abstract}
The oxidation kinetics of fluorenone hydrazone $(\mathrm{FH})$ using potassium permanganate in alkaline medium were measured at a constant ionic strength of $0.1 \mathrm{~mol} \mathrm{dm}^{-3}$ and at $25^{\circ} \mathrm{C}$ using UV/VIS spectrophotometer. A first-order kinetics has been monitored in the reaction of $\mathrm{FH}$ with respect to [permanganate]. Less-than-unit order dependence of the reaction on $[\mathrm{FH}]$ and $\left[\mathrm{OH}^{-}\right]$ was revealed. No pronounced effect on the reaction rate by increasing ionic strength was recorded. Intervention of free radicals was observed in the reaction. The reaction mechanism describing the kinetic results was illustrated which involves formation of 1:1 intermediate complex between fluorenone hydrazones and the active species of permanganate. 9H-Fluorenone as the corresponding ketone was found to be the final oxidation product of fluorenone hydrazone as confirmed by GC/MS analysis and FT-IR spectroscopy. The expression rate law for the oxidation reaction was deduced. The reaction constants and mechanism have been evaluated. The activation parameters associated with the rate-limiting step of the reaction, along with the thermodynamic quantities of the equilibrium constants, have been calculated and discussed.
\end{abstract}

\section{Introduction}

Fluorene and its derivatives (FLs) are a unique class of polycyclic aromatic hydrocarbons (PAHs) which exist in the fossil fuels and petrogenic sources burning of gasoline $[1,2]$. Recently, studies on the exhaust emitting of different types of reformulated diesel fuels showed presence of fluorene as a precedence compound and isomers of methyl fluorene as a hesitant compound in the exhaust [3]. The fluorene unit is regularly employed in the growth of an assortment of visual devices with latent application as dye-sensitized solar cells [4], polymer light-emitting diodes $[5,6]$, and other electroemissive materials [7]. In addition, fluorene based systems possess sole photophysical properties such as high fluorescent quantum yield, huge photostability, and excellent hole-transporting properties $[8,9]$. Furthermore, fluorene is one of the highest plentiful polycyclic aromatic hydrocarbons (PAHs) in the surroundings due to its high volatility. Established to be a neurotoxicant through mouthful of air, it was also recognized as a contributive $\mathrm{PAH}$ to food contagion. Fluorene compounds with intrinsic rigid structures have been attracting much consideration as organic functional materials because of their promising physical and chemical properties such as glass transition temperatures, good solubility, and their amorphous nature, which make them very promising as a move toward optic electric materials [10,11]. In addition, hydrazone derivatives were found to be biologically important class of compounds [12]. Hydrazone derivatives were found in natural and synthetic products of biological interest [13]. Literature studies revealed that hydrazones and the different substituted derivatives showed a broad spectrum of biological activities. Furthermore, fluorenone hydrazones are used as precursors for the synthesis of photochromic di- and tetrahydroindolizines [14-16] and more recently as efficient corrosion inhibitors [17].

Potassium permanganate is extensively used as an oxidizing agent for numerous organic molecules in various media [18-24]. The oxidation reaction mechanisms by permanganate 




Fluorenone hydrazone

9H-Fluorenone

Figure 1

are governed by $\mathrm{pH}$ of the medium [25]. Among six oxidation states of $\mathrm{Mn}(\mathrm{II})$ to $\mathrm{Mn}(\mathrm{VII})$, permanganate, $\mathrm{Mn}(\mathrm{VII})$, is found to be the most powerful oxidation state in both acid and alkaline media. By using permanganate as oxidizing agent, it is understandable that the $\mathrm{Mn}$ (VII) in permanganate is reduced to a variety of oxidation states in acidic, alkaline, and neutral media.

To the best of our knowledge, there are no reports on the kinetics and mechanism of oxidation of fluorenone hydrazone. This motivates us to investigate the kinetics and mechanism of oxidation of fluorenone hydrazone with permanganate ion in alkaline medium. The objectives of the present study aimed to shed more light and establish the most favorable conditions affecting oxidation of such noteworthy compound and to elucidate a plausible oxidation reaction mechanism.

\section{Experimental}

2.1. Materials. The chemicals used in the current work were of Aldrich grades. Fluorenone hydrazone was prepared according to the described procedures with some modifications $[26,27]$. The synthesized fluorenone hydrazone was confirmed by both spectroscopic and analytical tools. All solvents used were of spectroscopic grade and used without further purification. The solvents used were checked for the absence of absorbing or any fluorescent impurities. Potassium permanganate fresh solution was prepared and standardized as reported [28]. Sodium hydroxide and sodium perchlorate were used to vary the alkalinity and ionic strength of reaction medium, respectively.

2.2. Kinetic Measurements. The kinetic measurements were followed under pseudo-first-order conditions where fluorenone hydrazone substrate (abbreviated by FH) existed in a large excess over that of permanganate. Initiation of the reaction was done by mixing the formerly thermostated solutions of permanganate and substrate that also contained the required amounts of $\mathrm{NaOH}$ and $\mathrm{NaClO}_{4}$. The course of the reaction was followed up to not less than two half-lives by monitoring the absorbance of permanganate as a function of time at its absorption maximum $(\lambda=525 \mathrm{~nm})$, whereas the other constituents of the reaction mixture were not absorbed considerably at the determined wavelength. The melting points of fluorenone derivatives were recorded using Gallenkamp melting point apparatus. NMR was recorded on



FIGURE 2: GC/MS analysis for detection of the oxidation product 9H-fluorenone $(m / z=180)$.

Bruker Avance $400 \mathrm{MHz}$ with $\mathrm{CDCl}_{3}$ and $\mathrm{CDCl}_{3}$ as solvent with tetramethylsilane (TMS) as the internal reference. Chemical shifts were related to that of the solvent. GCMass spectra were recorded on Shimadzu GCMS-QP1000 EX mass spectrometer at $70 \mathrm{eV}$. The absorption measurements were done in a temperature-controlled Shimadzu UV-VISNIR-3600 double-beam spectrophotometer. The reactions temperature was controlled to $\pm 0.1^{\circ} \mathrm{C}$.

First-order plots of $\ln$ (absorbance) versus time were recorded to be straight lines up to at least $80 \%$ of the reaction completion and the observed first-order rate constants $\left(k_{\mathrm{obs}}\right)$ were calculated as the gradients of such plots. Ordinary values of at least two independent determinations of the rate constants were taken for the analysis. The rate constants were reproducible to $2-3 \%$. The orders of the reaction with admiration to the reactants were calculated from the slopes of the $\log k_{\text {obs }}$ versus $\log$ (concentration) plots by varying the concentrations of both substrate and alkali, in turn, while keeping other conditions constant.

\section{Results and Discussion}

3.1. Stoichiometry and Product Analysis. The stoichiometry was analyzed periodically by both titrimetric and spectrophotometric techniques at $\left[\mathrm{OH}^{-}\right]=0.01$ and $I=0.1 \mathrm{~mol} \mathrm{dm}^{-3}$ at $25^{\circ} \mathrm{C}$. The results indicate expenditure of four permanganate ions for one molecule of fluorenone hydrazone to yield the oxidation products as shown in Figure 1.

Figure 1 is in good agreement with the results of products analysis as confirmed by the head-space GC/MS which revealed a molecular ion peak $\left[\mathrm{M}^{+}, 100 \%\right]$ at 180 related to $9 \mathrm{H}$-fluoren-9-one (Figure 2). The mass spectrometry fragmentation pattern for $9 \mathrm{H}$-fluoren-9-one showed the following signals: $m / z$ : 180.06 (100.0\%), 181.06 (14.2\%), 182.06 (1.1\%), 152.23 (33.4\%), 125.46 (10.19), and 102.35 (1.6). 


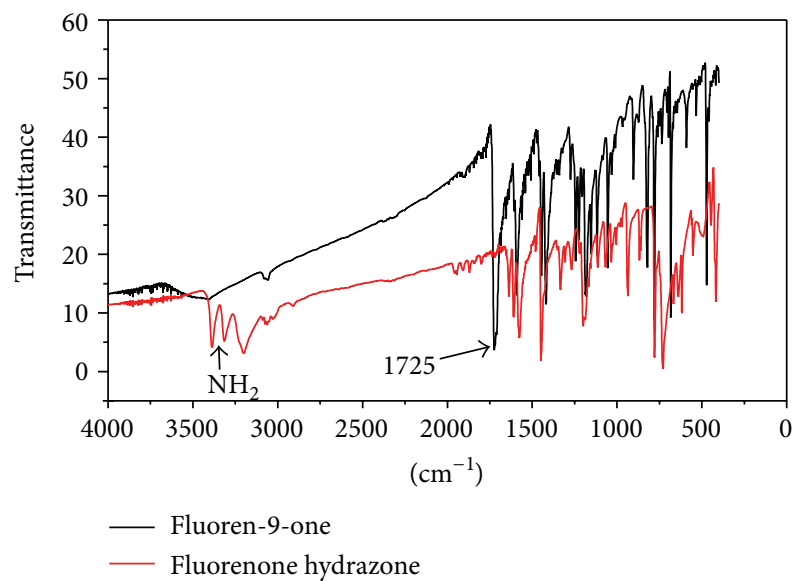

FIGURE 3: FT-IR spectra of fluorenone hydrazone (red line) and the oxidized product $9 \mathrm{H}$-fluorenone (black line).

Further assignment of the oxidation product was done by the help of FT-IR spectra as represented in Figure 3 for fluorenone hydrazone and its oxidation product, 9H-fluoren-9one. The product $9 \mathrm{H}$-fluoren-9-one showed a very strong signal at $1725 \mathrm{~cm}^{-1}$ corresponding to the $(\mathrm{C}=\mathrm{O})$ group with disappearance of amino group at signals at 3388 and $3316 \mathrm{~cm}^{-1}$. In addition, the fingerprints of the oxidation product are different than before oxidation process.

3.2. Time-Resolved Spectra. Time-resolved spectra during the oxidation of fluorenone hydrazone by alkaline permanganate are represented in Figure 4. The main characteristic feature manifested in the figure is the gradual decay of permanganate band at its absorption maximum $(\lambda=525 \mathrm{~nm})$ as a result of reduction of permanganate by fluorenone hydrazone derivatives.

3.3. Effect of Permanganate Concentration. Permanganate ion oxidant was diverse in the concentration range of $1.0 \times 10^{-4}$ to $8.0 \times 10^{-4} \mathrm{~mol} \mathrm{dm}^{-3}$, while the rest of the reactant concentrations were kept constant. Both $\mathrm{pH}$ and temperature were also kept constant. It has been found that plots of $\ln$ (absorbance) versus time were linear up to about $80 \%$ of the reaction achievement. Furthermore, the increase in the oxidant concentration did not change the oxidation rate as listed in Table 1. These results prove and confirm the firstorder reaction with respect to the oxidant.

3.4. Effect of Fluorenone Hydrazone Concentration. The observed first-order rate constant $\left(k_{\text {obs }}\right)$ was measured at diverse concentrations of the reductant fluorenone hydrazone keeping others constant. A plot of $k_{\text {obs }}$ versus [FH] was found to be linear with a positive intercept on $k_{\mathrm{obs}}$ axis (Figure 5) confirming less-than-unit order dependence with respect to the reductant concentration.

3.5. Effect of Alkali Concentration. The influence of alkali on the reaction rate was deliberated at various $\left[\mathrm{OH}^{-}\right]$, keeping



FIGURE 4: Time-resolved spectra during the oxidation of fluorenone by alkaline permanganate: $[\mathrm{FH}]=8.0 \times 10^{-3},\left[\mathrm{MnO}_{4}{ }^{-}\right]=4.0 \times 10^{-4}$, $\left[\mathrm{OH}^{-}\right]=0.02$, and $I=0.1 \mathrm{~mol} \mathrm{dm}^{-3}$ at $25^{\circ} \mathrm{C}$. Scanning time intervals are $1 \mathrm{~min}$.

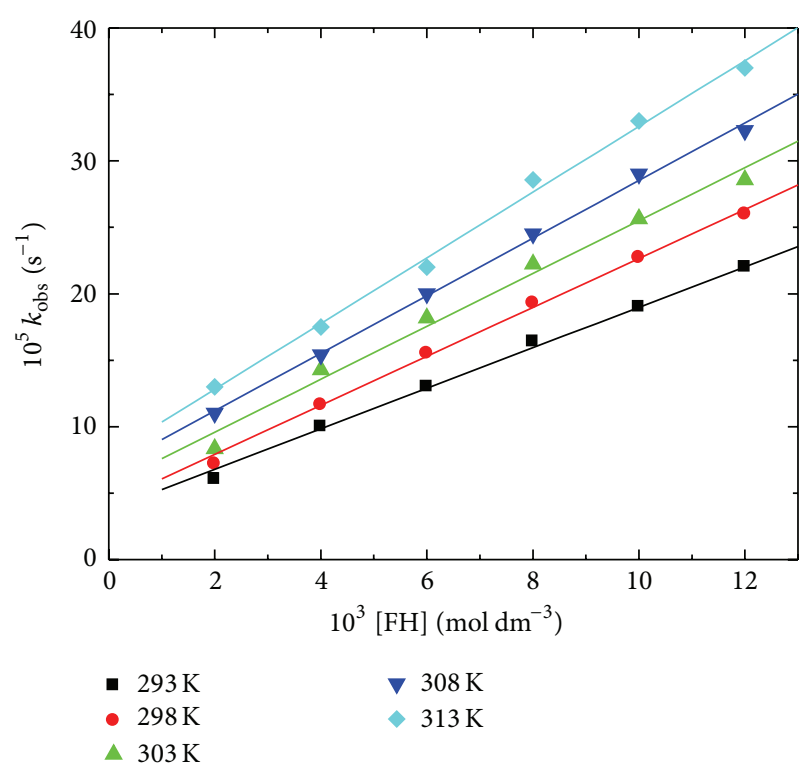

Figure 5: Plots of the observed first-order rate constants $\left(k_{\mathrm{obs}}\right)$ versus $[\mathrm{FH}]$, at different temperatures, in the oxidation of fluorenone hydrazone by alkaline permanganate: $\left[\mathrm{MnO}_{4}^{-}\right]=4.0 \times 10^{-4}$, $\left[\mathrm{OH}^{-}\right]=0.02$, and $I=0.1 \mathrm{~mol} \mathrm{dm}{ }^{-3}$.

all other reactant concentrations constant. An increase in the rate constant with increasing alkali concentration was achieved (Table 1). A plot of $\log k_{\text {obs }}$ versus $\log \left[\mathrm{OH}^{-}\right]$was found to be linear with a slope of 0.75 (figure not shown), suggesting that the reaction order with respect to $\left[\mathrm{OH}^{-}\right]$was less than unity.

3.6. Effect of Ionic Strength. The effect of the ionic strength was studied through varying the concentration of $\mathrm{NaClO}_{4}$ in the reaction medium at constant concentrations of permanganate, fluorenone hydrazone, and alkali. It was found that 
TABLE 1: Effect of variation of $\left[\mathrm{MnO}_{4}^{-}\right],[\mathrm{FH}],\left[\mathrm{OH}^{-}\right]$, and $I$ on the observed first-order rate constants $\left(k_{\mathrm{obs}}\right)$ in the oxidations of fluorenone hydrazone by alkaline permanganate at $25^{\circ} \mathrm{C}$.

\begin{tabular}{|c|c|c|c|c|}
\hline $10^{4}\left[\mathrm{MnO}_{4}^{-}\right]\left(\mathrm{mol} \mathrm{dm}^{-3}\right)$ & $10^{3}[\mathrm{FH}]\left(\mathrm{mol} \mathrm{dm}^{-3}\right)$ & $10^{2}\left[\mathrm{OH}^{-}\right]\left(\mathrm{mol} \mathrm{dm}^{-3}\right)$ & $I\left(\mathrm{~mol} \mathrm{dm}^{-3}\right)$ & $10^{4} k_{\text {obs }}\left(\mathrm{s}^{-1}\right)$ \\
\hline 1.0 & 8.0 & 2.0 & 0.1 & 19.8 \\
\hline 2.0 & 8.0 & 2.0 & 0.1 & 20.2 \\
\hline 3.0 & 8.0 & 2.0 & 0.1 & 19.2 \\
\hline 4.0 & 8.0 & 2.0 & 0.1 & 19.6 \\
\hline 6.0 & 8.0 & 2.0 & 0.1 & 18.3 \\
\hline 8.0 & 8.0 & 2.0 & 0.1 & 18.9 \\
\hline 4.0 & 2.0 & 2.0 & 0.1 & 7.3 \\
\hline 4.0 & 4.0 & 2.0 & 0.1 & 12.0 \\
\hline 4.0 & 6.0 & 2.0 & 0.1 & 15.8 \\
\hline 4.0 & 8.0 & 2.0 & 0.1 & 19.6 \\
\hline 4.0 & 10.0 & 2.0 & 0.1 & 22.8 \\
\hline 4.0 & 12.0 & 2.0 & 0.1 & 25.6 \\
\hline 4.0 & 8.0 & 0.5 & 0.1 & 9.8 \\
\hline 4.0 & 8.0 & 1.0 & 0.1 & 14.2 \\
\hline 4.0 & 8.0 & 1.5 & 0.1 & 17.4 \\
\hline 4.0 & 8.0 & 2.0 & 0.1 & 19.6 \\
\hline 4.0 & 8.0 & 3.0 & 0.1 & 23.6 \\
\hline 4.0 & 8.0 & 4.0 & 0.1 & 27.3 \\
\hline 4.0 & 8.0 & 2.0 & 0.1 & 19.6 \\
\hline 4.0 & 8.0 & 2.0 & 0.2 & 18.9 \\
\hline 4.0 & 8.0 & 2.0 & 0.3 & 20.7 \\
\hline 4.0 & 8.0 & 2.0 & 0.4 & 19.2 \\
\hline 4.0 & 8.0 & 2.0 & 0.5 & 18.9 \\
\hline 4.0 & 8.0 & 2.0 & 0.6 & 20.2 \\
\hline
\end{tabular}

Experimental error is $\pm 3 \%$.

variation in ionic strength did not affect the oxidation rate as observed from the data listed in Table 1.

3.7. Effect of Temperature. The oxidation rate was recorded at five different temperatures, 293, 298, 303, 308, and $313 \mathrm{~K}$ under varying the concentrations of fluorenone hydrazone and alkali at constant ionic strength. The activation parameters of the rate constant of the slow step $\left(k_{1}\right)$ along with thermodynamic parameters of the equilibrium constants involved in the reaction mechanism were evaluated using Arrhenius and Eyring equations and were listed in Table 2.

3.8. Polymerization Study. To check the existence of free radicals in the reaction under investigation, the reactions mixtures were mixed with identified quantities of acrylonitrile monomer and stored for 6 hours under dry nitrogen condition. On dilution with methanol, white precipitates were formed, indicating the participation of free radicals in the oxidation reactions. The blank experiments which were carried out with either permanganate or every substrate with acrylonitrile did not induce polymerization under the same experimental conditions.

3.9. Reaction Mechanism. Permanganate ion is found to be a powerful oxidant in aqueous alkaline media and exhibits some of oxidation states such as $\mathrm{Mn}(\mathrm{VII}), \mathrm{Mn}(\mathrm{V})$, and $\mathrm{Mn}(\mathrm{VI})$. At $\mathrm{pH}>12$, the reduction product of $\mathrm{Mn}(\mathrm{VII})$ is stable $\mathrm{Mn}(\mathrm{VI})$ and no further reduction is observed $[29,30]$. The formation of a manganate(VI) intermediate was confirmed by the green color observed as the reactions proceeded $[31,32]$ which undergoes a slow decay to give rise to the final oxidation products. The yellow color persisted after achievement of the oxidation reactions; then, finally, discrete brown $\mathrm{MnO}_{2}$ sol was observed confirming that $\mathrm{Mn}(\mathrm{V})$ species, hypomanganate $(\mathrm{V})$, formed and subsequently decomposed to $\mathrm{Mn}(\mathrm{IV})$ sol [33]. The latter was coagulated by aging to give a colloidal precipitate of $\mathrm{Mn}(\mathrm{IV}) \mathrm{O}_{2}$.

It was reported $[34,35]$ that permanganate ion in aqueous alkaline media combines with alkali to produce an alkalipermanganate species, $\left[\mathrm{MnO}_{4} \cdot \mathrm{OH}\right]^{2-}$, in a preequilibrium step, as shown in Scheme 1. This is consistent with the apparent order of less than unity with respect to the alkali. The formation of $\left[\mathrm{MnO}_{4} \cdot \mathrm{OH}\right]^{2-}$ in the present systems is further supported by the plots of $1 / k_{\text {obs }}$ versus $1 /\left[\mathrm{OH}^{-}\right]$shown in Figure 7, which are linear with nonzero intercepts.

Many investigators [18-24] have suggested that most of the permanganate ion oxidation reactions in neutral and alkaline media proceed through intermediate complexes formation between the oxidant and substrates. The kinetic evidence for such complex was established by the linearity of the plots between $1 / k_{\mathrm{obs}}$ and $1 /[\mathrm{FH}]$, Figure 6 , in favor of 
TABLE 2: Values of $k_{1}, K_{1}$, and $K_{2}$ (at different temperatures), activation parameters associated with the slow step $\left(k_{1}\right)$, and thermodynamic parameters of the equilibrium constants $\left(K_{1}\right.$ and $\left.K_{2}\right)$ in the oxidation of fluorenone hydrazone by alkaline permanganate: $\left[\mathrm{MnO}_{4}^{-}\right]=4.0 \times 10^{-4},[\mathrm{FH}]=8.0 \times 10^{-3},\left[\mathrm{OH}^{-}\right]=0.02$, and $I=$ $0.1 \mathrm{~mol} \mathrm{dm}^{-3}$.

(a) Values of $k_{1}, K_{1}$, and $K_{2}$ (at different temperatures)

\begin{tabular}{lccccc}
\hline \multirow{2}{*}{ Constant } & \multicolumn{5}{c}{ Temperature (K) } \\
& 293 & 298 & 303 & 308 & 313 \\
\hline $10^{4} k_{1}\left(\mathrm{dm}^{3} \mathrm{~mol}^{-1} \mathrm{~s}^{-1}\right)$ & 3.71 & 4.50 & 5.39 & 6.41 & 7.41 \\
$K_{1}\left(\mathrm{dm}^{3} \mathrm{~mol}^{-1}\right)$ & 15.62 & 17.48 & 20.11 & 24.74 & 29.08 \\
$10^{-2} K_{2}\left(\mathrm{dm}^{3} \mathrm{~mol}^{-1}\right)$ & 4.73 & 4.16 & 3.61 & 3.23 & 3.06 \\
\hline
\end{tabular}

(b) Activation parameters associated with the slow step $\left(k_{1}\right)$

\begin{tabular}{lccc}
\hline$\Delta S^{\ddagger} \mathrm{J} \mathrm{mol}^{-1} \mathrm{~K}^{-1}$ & $\Delta H^{\ddagger} \mathrm{kJ} \mathrm{mol}^{-1}$ & $\Delta G_{298}^{\neq} \mathrm{kJ} \mathrm{mol}^{-1}$ & $E_{a}^{\neq} \mathrm{kJ} \mathrm{mol}^{-1}$ \\
\hline$-103.02 \pm 4.1$ & $26.52 \pm 1.2$ & $57.22 \pm 0.4$ & $27.06 \pm 1.3$
\end{tabular}

(c) Thermodynamic parameters associated with the equilibrium constants $\left(K_{1}\right.$ and $\left.K_{2}\right)$

\begin{tabular}{lccc}
\hline $\begin{array}{l}\text { Equilibrium } \\
\text { constant }\end{array}$ & $\Delta H^{0} \mathrm{~kJ} \mathrm{~mol}^{-1}$ & $\Delta G_{298}^{0} \mathrm{~kJ} \mathrm{~mol}^{-1}$ & $\Delta S^{0} \mathrm{~J} \mathrm{~mol}^{-1} \mathrm{~K}^{-1}$ \\
\hline$K_{1}$ & 24.28 & -7.08 & 105.25 \\
$K_{2}$ & -17.18 & -14.94 & -7.51 \\
\hline
\end{tabular}



FIGURE 6: Plots of $1 / k_{\mathrm{obs}}$ versus $1 /[\mathrm{FH}]$, at different temperatures, in the oxidation of fluorenone hydrazone by alkaline permanganate: $\left[\mathrm{MnO}_{4}^{-}\right]=4.0 \times 10^{-4},\left[\mathrm{OH}^{-}\right]=0.02$, and $I=0.1 \mathrm{~mol} \mathrm{dm}{ }^{-3}$.

possible formation of a transient complex flanked by oxidant and substrate comparable with the well-known MichaelisMenten mechanism [36] for enzyme-substrate reactions. The observed insignificant effect of ionic strength on the reaction rate implies the association of an ion and a neutral molecule



FIGURE 7: Plots of $1 / k_{\text {obs }}$ versus $1 /\left[\mathrm{OH}^{-}\right]$, at different temperatures, in the oxidation of fluorenone hydrazone by alkaline permanganate: $\left[\mathrm{MnO}_{4}^{-}\right]=4.0 \times 10^{-4},[\mathrm{FH}]=8.0 \times 10^{-3}$, and $I=0.1 \mathrm{~mol} \mathrm{dm}{ }^{-3}$.

[37], that is, between neutral fluorenone hydrazone and negative alkali-permanganate species.

In view of the above arguments, the reaction mechanism shown in Scheme 1 may be suggested. This involves attack of the active species of permanganate, $\left[\mathrm{MnO}_{4} \cdot \mathrm{OH}\right]^{2-}$, on the fluorenone hydrazone substrate leading to the formation of a complex (C) in a preequilibrium step. In this complex, one electron is transferred from the substrate to permanganate. Under slow cleavage of the complex, the formation of a free radical intermediate derived from the substrate and manganate(VI) transient species has been monitored. The intermediate radical is rapidly attacked by another alkalipermanganate species to yield the corresponding diazoderivative which on further oxidation by two moles of permanganate species gives the corresponding ketone (fluorenone) as the final oxidation product.

The relationship between reaction rate and substrate $(\mathrm{FH})$, hydroxyl ion, and oxidant concentrations can be deduced (see Appendix) to give the following equation:

$$
\text { Rate }=\frac{k_{1} K_{1} K_{2}[\mathrm{FH}]\left[\mathrm{OH}^{-}\right]\left[\mathrm{MnO}_{4}^{-}\right]}{1+K_{1}\left[\mathrm{OH}^{-}\right]+K_{1} K_{2}[\mathrm{FH}]\left[\mathrm{OH}^{-}\right]} .
$$

The rate law under pseudo-first-order condition can be expressed by

$$
\text { Rate }=\frac{-d\left[\mathrm{MnO}_{4}^{-}\right]}{d t}=k_{\mathrm{obs}}\left[\mathrm{MnO}_{4}^{-}\right] .
$$




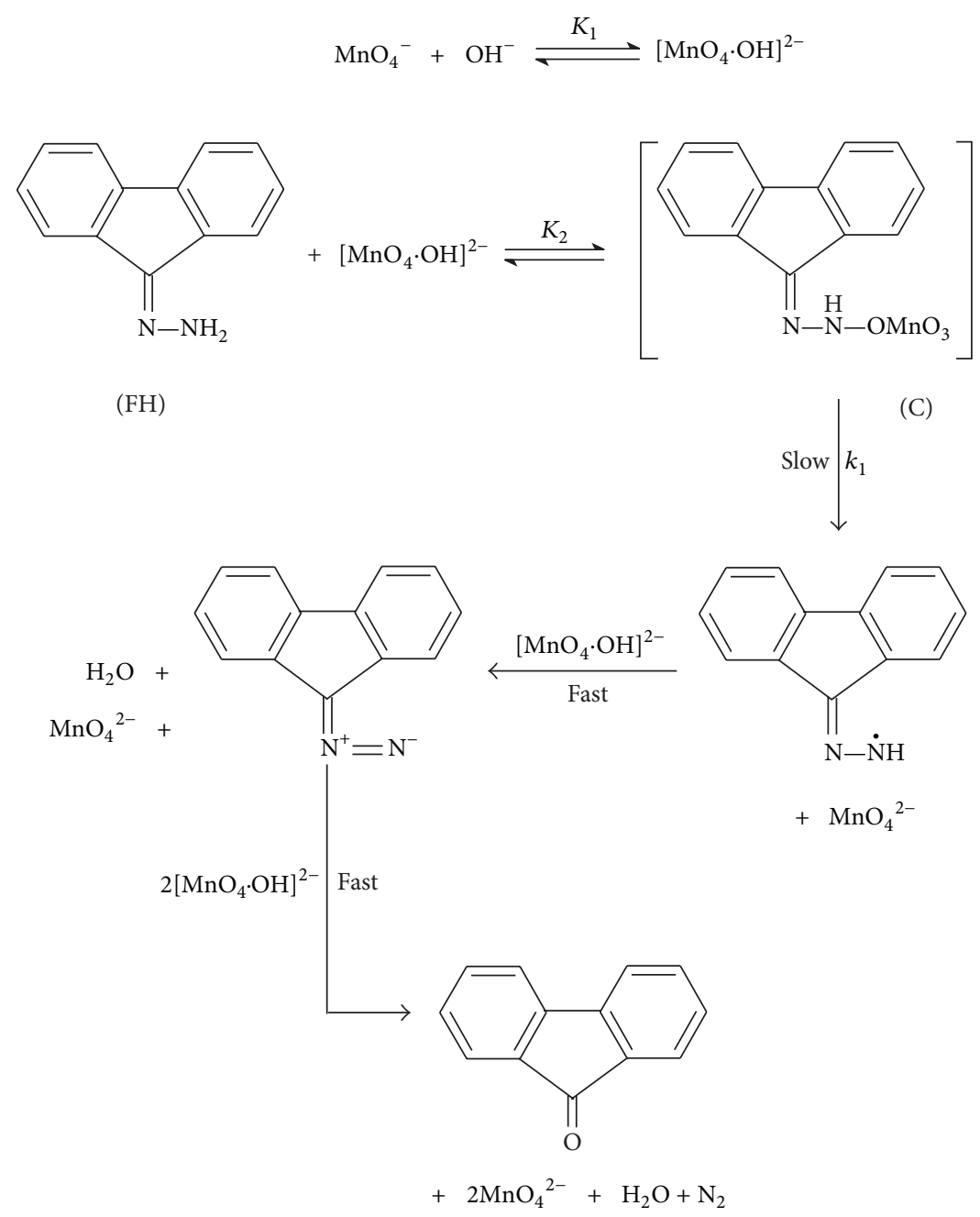

SCHEME 1: Mechanism of oxidation of fluorenone hydrazone by alkaline permanganate.

Comparing (1) and (2) and with rearrangement, we obtain the following equations:

$$
\begin{aligned}
\frac{1}{k_{\mathrm{obs}}}= & \left(\frac{1+K_{1}\left[\mathrm{OH}^{-}\right]}{k_{1} K_{1} K_{2}\left[\mathrm{OH}^{-}\right]}\right) \frac{1}{[\mathrm{FH}]}+\frac{1}{k_{1}} \\
\frac{1}{k_{\mathrm{obs}}}= & \left(\frac{1}{k_{1} K_{1} K_{2}[\mathrm{FH}]}\right) \frac{1}{\left[\mathrm{OH}^{-}\right]} \\
& +\left(\frac{1}{k_{1} K_{2}} \frac{1}{[\mathrm{FH}]}+\frac{1}{k_{1}}\right) .
\end{aligned}
$$

According to (3) and (4), with other conditions being constant, plots of $1 / k_{\text {obs }}$ versus $1 /[\mathrm{FH}]$ at constant $\left[\mathrm{OH}^{-}\right]$and $1 / k_{\text {obs }}$ versus $1 /\left[\mathrm{OH}^{-}\right]$at constant $[\mathrm{FH}]$ should be linear with positive intercepts on $1 / k_{\mathrm{obs}}$ axes and are certainly found to be so as shown in Figures 6 and 7, respectively. The slopes and intercepts of such plots lead to calculation of values of $k_{1}, K_{1}$, and $K_{2}$ (at different temperatures) as listed in Table 2. The obtained values of $K_{1}$ are in a good agreement with those reported in the literature [18-20]. Also, the activation parameters of $k_{1}$ along with thermodynamic parameters of $K_{1}$ and $K_{2}$ were calculated and were listed also in Table 2.

It has been previously reported [38] that the entropy of activation tends to be more negative for reactions of innersphere nature, whereas the reactions of positive $\Delta S^{\neq}$values proceed via outer-sphere mechanism. The obtained large negative values of entropy of activation (Table 2 ) suggest that one-electron transfer of inner-sphere nature is the more plausible mechanism for the current oxidation reaction. On the other hand, positive values of both $\Delta H^{\neq}$and $\Delta G^{\neq}$specify that the formation of the complex is endothermic and nonspontaneous, respectively.

\section{Conclusions}

The kinetics of oxidation of fluorenone hydrazone by alkaline permanganate has been studied. The oxidation product of fluorenone hydrazone was identified by GC/MS and FT-IR analyses as the corresponding ketone (9H-fluorenone). The 
reaction constants involved in the reaction mechanism have been evaluated. The activation and thermodynamic parameters have been evaluated and discussed.

\section{Appendix}

\section{Derivation of the Rate Law Expression}

According to suggested mechanistic scheme,

$$
\begin{aligned}
\text { Rate } & =\frac{-d\left[\mathrm{MnO}_{4}^{-}\right]}{d t}=k_{1}[\mathrm{C}] \\
K_{1} & =\frac{\left[\mathrm{MnO}_{4} \cdot \mathrm{OH}^{2-}\right]}{\left[\mathrm{MnO}_{4}^{-}\right]\left[\mathrm{OH}^{-}\right]} .
\end{aligned}
$$

Therefore,

$$
\begin{aligned}
{\left[\mathrm{MnO}_{4} \cdot \mathrm{OH}^{2-}\right] } & =K_{1}\left[\mathrm{MnO}_{4}^{-}\right]\left[\mathrm{OH}^{-}\right] \\
K_{2} & =\frac{[\mathrm{C}]}{[\mathrm{FH}]\left[\mathrm{MnO}_{4} \cdot \mathrm{OH}^{2-}\right]} .
\end{aligned}
$$

Thus,

$$
[\mathrm{C}]=K_{2}[\mathrm{FH}]\left[\mathrm{MnO}_{4} \cdot \mathrm{OH}^{2-}\right] .
$$

Substituting (A.3) into (A.5) leads to

$$
[\mathrm{C}]=K_{1} K_{2}[\mathrm{FH}]\left[\mathrm{OH}^{-}\right]\left[\mathrm{MnO}_{4}^{-}\right] .
$$

Substituting (A.6) into (A.1) yields

$$
\text { Rate }=k_{1} K_{1} K_{2}[\mathrm{FH}]\left[\mathrm{OH}^{-}\right]\left[\mathrm{MnO}_{4}^{-}\right] .
$$

The total concentration of fluorenone hydrazone is given by

$$
[\mathrm{FH}]_{\mathrm{T}}=[\mathrm{FH}]_{\mathrm{F}}+[\mathrm{C}],
$$

where $[\mathrm{FH}]_{\mathrm{T}}$ and $[\mathrm{FH}]_{\mathrm{F}}$ stand for total and free concentrations of the substrate.

Substituting (A.6) into (A.8) gives

$$
\begin{aligned}
{[\mathrm{FH}]_{\mathrm{T}} } & =[\mathrm{FH}]_{\mathrm{F}}+K_{1} K_{2}[\mathrm{FH}]\left[\mathrm{OH}^{-}\right]\left[\mathrm{MnO}_{4}^{-}\right] \\
{[\mathrm{FH}]_{\mathrm{T}} } & =[\mathrm{FH}]_{\mathrm{F}}\left(1+K_{1} K_{2}\left[\mathrm{OH}^{-}\right]\left[\mathrm{MnO}_{4}^{-}\right]\right) .
\end{aligned}
$$

Therefore,

$$
[\mathrm{FH}]_{\mathrm{F}}=\frac{[\mathrm{FH}]_{\mathrm{T}}}{1+K_{1} K_{2}\left[\mathrm{OH}^{-}\right]\left[\mathrm{MnO}_{4}^{-}\right]} .
$$

Similarly,

$$
\begin{aligned}
& {\left[\mathrm{MnO}_{4}^{-}\right]_{\mathrm{T}}=\left[\mathrm{MnO}_{4}^{-}\right]_{\mathrm{F}}+\left[\mathrm{MnO}_{4} \cdot \mathrm{OH}^{2-}\right]+[\mathrm{C}]} \\
& {\left[\mathrm{MnO}_{4}^{-}\right]_{\mathrm{T}}=\left[\mathrm{MnO}_{4}^{-}\right]_{\mathrm{F}}\left(1+K_{1}\left[\mathrm{OH}^{-}\right]\right.} \\
& \left.\quad+K_{1} K_{2}[\mathrm{FH}]\left[\mathrm{OH}^{-}\right]\left[\mathrm{MnO}_{4}^{-}\right]\right)
\end{aligned}
$$

$$
\left[\mathrm{MnO}_{4}^{-}\right]_{\mathrm{F}}=\frac{\left[\mathrm{MnO}_{4}^{-}\right]_{\mathrm{T}}}{1+K_{1}\left[\mathrm{OH}^{-}\right]+K_{1} K_{2}[\mathrm{FH}]\left[\mathrm{OH}^{-}\right]} .
$$

Also,

$$
\begin{aligned}
{\left[\mathrm{OH}^{-}\right]_{\mathrm{T}} } & =\left[\mathrm{OH}^{-}\right]_{\mathrm{F}}+\left[\mathrm{MnO}_{4} \cdot \mathrm{OH}^{2-}\right] \\
{\left[\mathrm{OH}^{-}\right]_{\mathrm{F}} } & =\frac{\left[\mathrm{OH}^{-}\right]_{\mathrm{T}}}{1+K_{1}\left[\mathrm{MnO}_{4}^{-}\right]}
\end{aligned}
$$

Substituting (A.11), (A.14), and (A.16) into (A.7) (and omitting "T" and "F" subscripts), we get

$$
\text { Rate }=\frac{k_{1} K_{1} K_{2}[\mathrm{FH}]\left[\mathrm{OH}^{-}\right]\left[\mathrm{MnO}_{4}^{-}\right]}{\left(1+K_{1} K_{2}\left[\mathrm{OH}^{-}\right]\left[\mathrm{MnO}_{4}^{-}\right]\right)\left(1+K_{1}\left[\mathrm{MnO}_{4}^{-}\right]\right)\left(1+K_{1}\left[\mathrm{OH}^{-}\right]+K_{1} K_{2}[\mathrm{FH}]\left[\mathrm{OH}^{-}\right]\right)}
$$

In view of low concentration of $\left[\mathrm{MnO}_{4}{ }^{-}\right]$used, both first and second terms in the denominator of (A.17) approximate to unity. Therefore, (A.17) becomes

$$
\text { Rate }=\frac{k_{1} K_{1} K_{2}[\mathrm{FH}]\left[\mathrm{OH}^{-}\right]\left[\mathrm{MnO}_{4}^{-}\right]}{1+K_{1}\left[\mathrm{OH}^{-}\right]+K_{1} K_{2}[\mathrm{FH}]\left[\mathrm{OH}^{-}\right]} .
$$

Under pseudo-first-order conditions, the rate law can be expressed as

$$
\text { Rate }=\frac{-d\left[\mathrm{MnO}_{4}^{-}\right]}{d t}=k_{\mathrm{obs}}\left[\mathrm{MnO}_{4}^{-}\right] .
$$

Comparing (A.18) and (A.19), the following relationship is obtained:

$$
k_{\mathrm{obs}}=\frac{k_{1} K_{1} K_{2}[\mathrm{FH}]\left[\mathrm{OH}^{-}\right]}{1+K_{1}\left[\mathrm{OH}^{-}\right]+K_{1} K_{2}[\mathrm{FH}]\left[\mathrm{OH}^{-}\right]} .
$$

And with rearrangement, the following equations are obtained:

$$
\begin{aligned}
\frac{1}{k_{\mathrm{obs}}}= & \left(\frac{1+K_{1}\left[\mathrm{OH}^{-}\right]}{k_{1} K_{1} K_{2}\left[\mathrm{OH}^{-}\right]}\right) \frac{1}{[\mathrm{FH}]}+\frac{1}{k_{1}} \\
\frac{1}{k_{\mathrm{obs}}}= & \left(\frac{1}{k_{1} K_{1} K_{2}[\mathrm{FH}]}\right) \frac{1}{\left[\mathrm{OH}^{-}\right]} \\
& +\left(\frac{1}{k_{1} K_{2}} \frac{1}{[\mathrm{FH}]}+\frac{1}{k_{1}}\right) .
\end{aligned}
$$

\section{Competing Interests}

The authors declare that there are no competing interests regarding the publication of this paper. 


\section{Acknowledgments}

The authors are highly indebted to the Chemistry Department, Umm Al-Qura University, for using of all instrumentation facilities. Saleh A. Ahmed is highly indebted to Professor Dr. Jochen Mattay, University of Bielefeld, Germany, for helping with some GC/MS and NMR measurements.

\section{References}

[1] T. Thormann, M. Rogojerov, B. Jordanov, and E. W. Thulstrup, "Vibrational polarization spectroscopy of fluorene: alignment in stretched polymers and nematic liquid crystals," Journal of Molecular Structure, vol. 509, no. 1-3, pp. 93-104, 1999.

[2] R. J. Irwin and N. P. Service, "Environmental contaminants encyclopedia fluorene," July 1997.

[3] E. Borrás, L. A. Tortajada-Genaro, M. Vázquez, and B. Zielinska, "Polycyclic aromatic hydrocarbon exhaust emissions from different reformulated diesel fuels and engine operating conditions," Atmospheric Environment, vol. 43, no. 37, pp. 5944-5952, 2009.

[4] X. Li, H. Lü, S. Wang, J. Guo, and J. Li, "Sensitizers of dyesensitized solar cells," Progress in Chemistry, vol. 23, no. 2-3, pp. 569-588, 2011.

[5] Z. Ma, J. Ding, Y. Cheng et al., "Synthesis and characterization of red light-emitting electrophosphorescent polymers with different triplet energy main chain," Polymer, vol. 52, no. 10, pp. 2189-2197, 2011.

[6] H.-Y. Wang, Q. Qian, K.-H. Lin et al., "Stable and good color purity white light-emitting devices based on random fluorene/spirofluorene copolymers doped with iridium complex," Journal of Polymer Science, Part B: Polymer Physics, vol. 50, no. 3, pp. 180-188, 2012.

[7] X. H. Yang, F. I. Wu, D. Neher, C. H. Chien, and C. F. Shu, "Polyfluorene-based semiconductors combined with various periodic table elements for organic electronics," Chemistry of Materials, vol. 20, pp. 1629-1635, 2008.

[8] O. A. Kucherak, P. Didier, Y. Mély, and A. S. Klymchenko, "Fluorene analogues of prodan with superior fluorescence brightness and solvatochromism," Journal of Physical Chemistry Letters, vol. 1, no. 3, pp. 616-620, 2010.

[9] Y.-J. Cheng, S.-H. Yang, and C.-S. Hsu, "Synthesis of conjugated polymers for organic solar cell applications," Chemical Reviews, vol. 109, no. 11, pp. 5868-5923, 2009.

[10] X. Xing, L. Zhang, R. Liu et al., "A deep-blue emitter with electron transporting property to improve charge balance for organic light-emitting device," ACS Applied Materials \& Interfaces, vol. 4, no. 6, pp. 2877-2880, 2012.

[11] J. Pina, J. S. S. de Melo, A. Eckert, and U. Scherf, "Unusual photophysical properties of conjugated, alternating indigo-fluorene copolymers," Journal of Materials Chemistry A, vol. 3, no. 12, pp. 6373-6382, 2015.

[12] L. Jin, J. Chen, B. Song et al., "Synthesis, structure, and bioactivity of $\mathrm{N}^{\prime}$-substituted benzylidene-3,4,5-trimethoxybenzohydrazide and 3-acetyl-2-substituted phenyl-5-(3,4,5-trimethoxyphenyl)-2,3-dihydro-1,3,4-oxadiazole derivatives," Bioorganic \& Medicinal Chemistry Letters, vol. 16, no. 19, pp. 5036-5040, 2006.

[13] A. John Maria Xavier, M. Thakur, and J. Margaret Marie, "Synthesis and spectral characterisation of hydrazone based 14membered octaaza macrocyclic Ni(II) complexes," Journal of Chemical and Pharmaceutical Research, vol. 4, no. 2, pp. 986990, 2012.
[14] S. A. Ahmed, Th. Hartmann, and H. Dürr, "Photochromism of dihydroindolizines: part VIII. First holographic image recording based on di- and tetrahydroindolizines photochromes," Journal of Photochemistry and Photobiology A: Chemistry, vol. 200, no. 1, pp. 50-56, 2008.

[15] S. A.-M. Ahmed and J.-L. Pozzo, "Photochromism of dihydroindolizines Part IX: first attempts towards efficient selfassembling organogelators based on photochromic dihydroindolizines and $N$-acyl-1, $\omega$-amino acid units," Journal of Photochemistry and Photobiology A: Chemistry, vol. 200, no. 1, pp. 5767, 2008.

[16] S. A.-M. Ahmed, "Photochromism of dihydroindolizines. Part II. Synthesis and photophysical properties of new photochromic IR-sensitive photoswitchable substituted fluorene- $9^{\prime}$ styrylquinolinedihydroindolizines," Journal of Physical Organic Chemistry, vol. 15, no. 7, pp. 392-402, 2002.

[17] B. A. AL Jahdaly, I. L. Althagafi, M. Abdallah, K. S. Khairou, and S. A. Ahmed, "Fluorenone hydrazone derivatives as efficient inhibitors of acidic and pitting corrosion of carbon steel," Journal of Materials and Environmental Science, vol. 7, no. 5, pp. 1798-1809, 2016.

[18] A. Fawzy, S. S. Ashour, and M. A. Musleh, "Base-catalyzed oxidation of $\mathrm{L}$-asparagine by alkaline permanganate and the effect of alkali metal ion catalysts: a kinetic and mechanistic approach," Reaction Kinetics, Mechanisms and Catalysis, vol. 111, no. 2, pp. 443-460, 2014.

[19] A. Fawzy and M. R. Shaaban, "Kinetic and mechanistic investigations on the oxidation of $N^{\prime}$-heteroaryl unsymmetrical formamidines by permanganate in aqueous alkaline medium," Transition Metal Chemistry, vol. 39, no. 4, pp. 379-386, 2014.

[20] A. Fawzy, I. A. Zaafarany, J. Alfahemi, and F. A. Tirkistani, "Base-catalyzed oxidation of aminotriazole derivative by permanganate ion in aqueous alkaline medium: a kinetic study," International Journal of Innovative Research in Science, Engineering and Technology, vol. 4, no. 8, pp. 6802-6814, 2015.

[21] B. H. Asghar and A. Fawzy, "Kinetic, mechanistic, and spectroscopic studies of permanganate oxidation of azinylformamidines in acidic medium, with autocatalytic behavior of manganese(II)," Journal of Saudi Chemical Society, 2014.

[22] A. Fawzy, S. S. Ashour, and M. A. Musleh, "Kinetics and mechanism of oxidation of L-histidine by permanganate ions in sulfuric acid medium," International Journal of Chemical Kinetics, vol. 46, no. 7, pp. 370-381, 2014.

[23] G. A. Ahmed, A. Fawzy, and R. M. Hassan, "Spectrophotometric evidence for the formation of short-lived hypomanganate $(\mathrm{V})$ and manganate(VI) transient species during the oxidation of $K$ carrageenan by alkaline permanganate," Carbohydrate Research, vol. 342, no. 10, pp. 1382-1386, 2007.

[24] I. A. Zaafarany, A. A. S. N. AlArifi, A. Fawzy et al., "Further evidence for detection of short-lived transient hypomanganate $(\mathrm{V})$ and manganate(VI) intermediates during oxidation of some sulfated polysaccharides by alkaline permanganate using conventional spectrophotometric techniques," Carbohydrate Research, vol. 345, no. 11, pp. 1588-1593, 2010.

[25] K. A. Gardner, L. L. Kuehnert, and J. M. Mayer, "Hydrogen atom abstraction by permanganate: oxidations of arylalkanes in organic solvents," Inorganic Chemistry, vol. 36, no. 10, pp. 20692078, 1997.

[26] S. A. Ahmed, "Photochromism of dihydroindolizines. Part III [1]. Synthesis and photochromic behavior of novel photochromic dihydroindolizines incorporating a cholesteryl moiety," Monatshefte für Chemie, vol. 135, no. 9, pp. 1173-1188, 2004. 
[27] S. A. Ahmed, K. S. Khairou, B. H. Asghar, H. A. Muathen, N. M. A. Nahas, and H. F. Alshareef, "Photochromism of tetrahydroindolizines. Part XIV: synthesis of cis-fixed conjugated photochromic pyridazinopyrrolo[1,2-b]isoquinolines incorporating carbon-rich linkers," Tetrahedron Letters, vol. 55, no. 14, pp. 2190-2196, 2014.

[28] R. M. Hassan, A. Fawzy, A. Alarifi, G. A. Ahmed, I. A. Zaafarany, and H. D. Takagi, "Base-catalyzed oxidation of some sulfated macromolecules: kinetics and mechanism of formation of intermediate complexes of short-lived manganate (VI) and/or hypomanganate $(\mathrm{V})$ during oxidation of iota- and lambdacarrageenan polysaccharides by alkaline permanganate," Journal of Molecular Catalysis A: Chemical, vol. 335, no. 1-2, pp. 3845, 2011.

[29] L. I. Simándi, M. Jáky, and Z. A. Schelly, "Short-lived manganate(VI) and manganate(V) intermediates in the permanganate oxidation of sulfite ion," Journal of the American Chemical Society, vol. 106, no. 22, pp. 6866-6867, 1984.

[30] L. I. Simándi, M. Jáky, C. R. Savage, and Z. A. Schelly, "Kinetics and mechanism of the permanganate ion oxidation of sulfite in alkaline solutions. The nature of short-lived intermediates," Journal of the American Chemical Society, vol. 107, no. 14, pp. 4220-4224, 1985.

[31] F. A. Cotton and G. Wilkinson, Advanced Inorganic Chemistry, John Wiley \& Sons, New York, NY, USA, 1980.

[32] R. M. Hassan, A. R. Dahy, S. Ibrahim, I. A. Zaafarany, and A. Fawzy, "Oxidation of some macromolecules. Kinetics and mechanism of oxidation of methyl cellulose polysaccharide by permanganate ion in acid perchlorate solutions," Industrial and Engineering Chemistry Research, vol. 51, no. 15, pp. 5424-5432, 2012.

[33] R. M. Hassan, "Alginate polyelectrolyte ionotropic gels. XIV. Kinetics and mechanism of formation of intermediate complex during the oxidation of alginate polysaccharide by alkaline permanganate with a spectrophotometric evidence of manganate (VI) transient species," Journal of Polymer Science, Part A: Polymer Chemistry, vol. 31, no. 1, pp. 51-59, 1993.

[34] R. G. Panari, R. B. Chougale, and S. T. Nandibewoor, "Oxidation of mandelic acid by alkaline potassium permanganate. A kinetic study," Journal of Physical Organic Chemistry, vol. 11, no. 7, pp. 448-454, 1998.

[35] L. A. De Oliveira, H. E. Toma, and E. Giesbrecht, "Kinetics of oxidation of free and coordinated dimethylsulfoxide with permanganate in aqueous solution," Inorganic and Nuclear Chemistry Letters, vol. 12, no. 2, pp. 195-203, 1976.

[36] L. Michaelis and M. L. Menten, "The kinetics of invertase action," Biochemistry Z, vol. 49, pp. 333-369, 1913.

[37] A. A. Frost and R. G. Person, Kinetics and Mechanism, Wiley Eastern, New Delhi, India, 1970.

[38] K. W. Hicks, D. L. Toppen, and R. G. Linck, "Inner-sphere electron-transfer reactions of vanadium(II) with azidoamine complexes of cobalt(III)," Inorganic Chemistry, vol. 11, no. 2, pp. 310-315, 1972. 

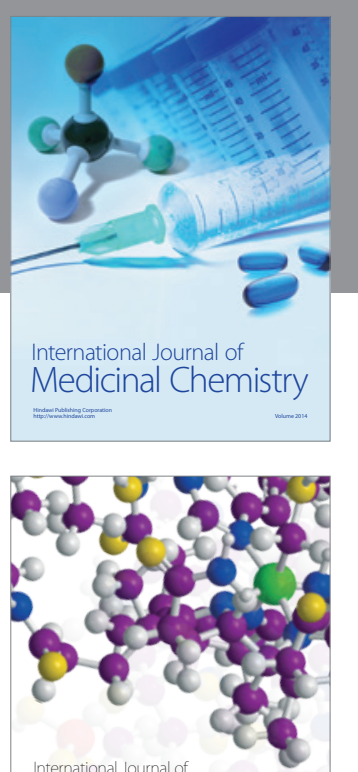

Carbohydrate Chemistry

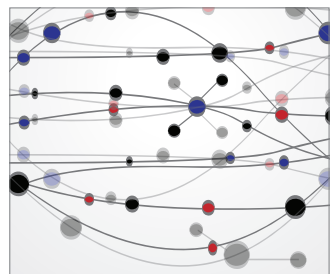

The Scientific World Journal
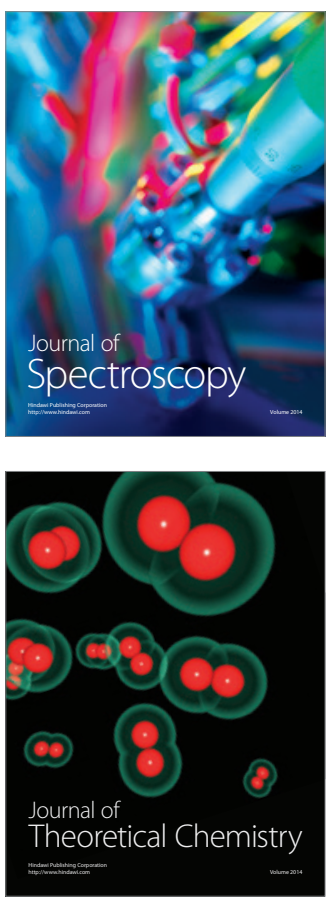
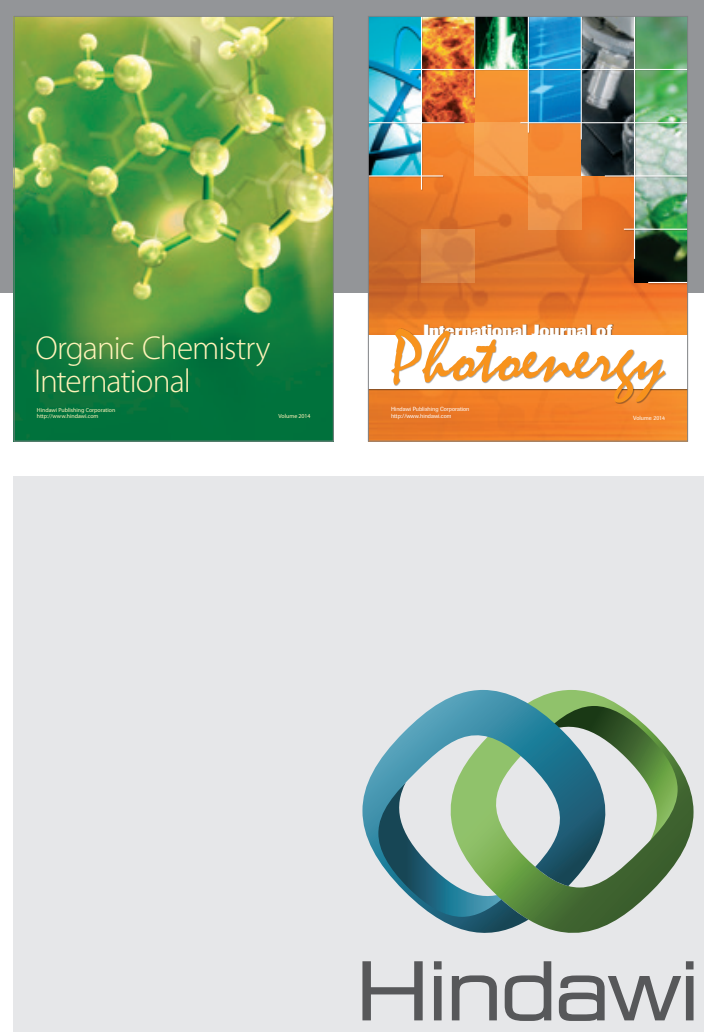

Submit your manuscripts at

http://www.hindawi.com

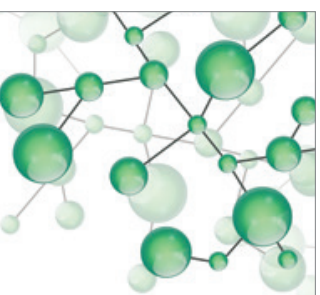

International Journal of

Inorganic Chemistry

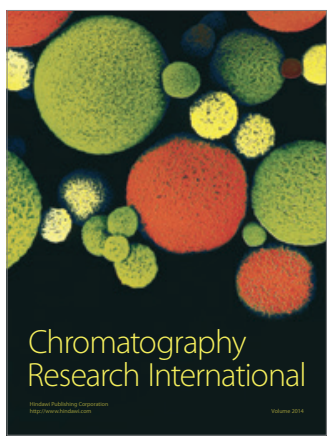

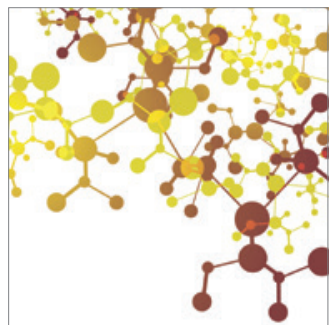

Applied Chemistry
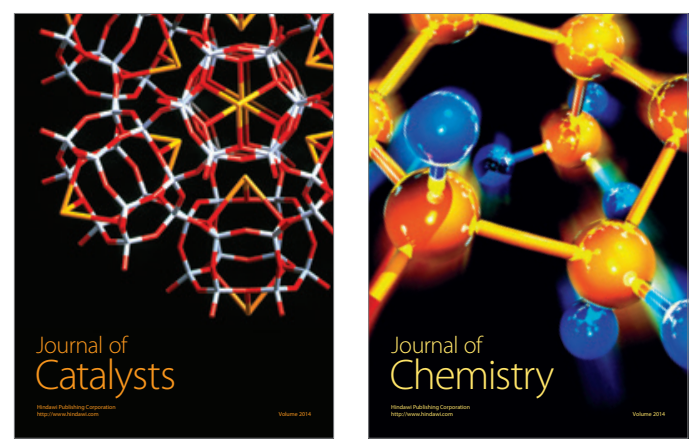
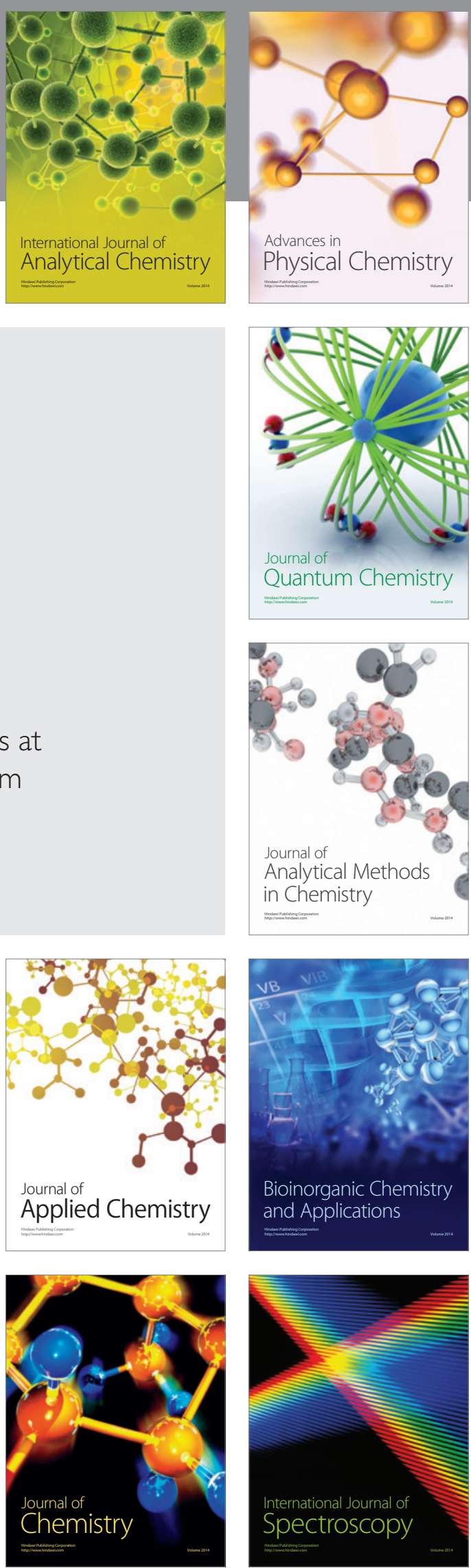